\title{
Introduction: New Approaches to Audiences and their Musics
}

\author{
RAFAL ZABOROWSKI, London School of Economics and Political Science
}

Why do we need a new approach to music audiences? The answer is complex and its various threads surface in all articles of this special issue, but the problem boils down to the underlining challenge of a visual bias in media research. It starts from the language (English - but similar phrases exist in in Polish and Japanese - and, I imagine, in a number of other languages): we look at issues, we shed light on challenges, we see challenges, we observe emerging patterns. But even beyond the linguistic sphere, the history of modern media research accentuates the focus on visual media. In audience studies this imbalance is felt especially strongly, as the word 'audience' stems from Latin audentia meaning 'a hearing', and later 'listeners' - and yet the audiences nowadays are rarely asked about things they hear or listen to. It has not always been so (the broadcast and radio effects studies of the 1930s and 1940s are examples of such approaches) but with the dawn of the television era, and later, the new media, the focus of audience research shifted towards the visual, the new, and, with the internet, the 'interactive'.

And so, while the academic trajectory of media audiences in reception studies may convey a powerful story of audience interpretation and reproduction of textual meanings, this has not always been the story of listening. Music and sound were more of an interest for musicology and sound studies rather than for media audience studies, which often resulted in an emphasis on formal, textual approaches. Yes, there have been valuable studies of music in everyday life (for instance Bull 2000 or DeNora 2000), however, on the whole, media and audience scholars have rarely approached 'listening': be it because it feels more passive than writing or reading (cf. Lacey 2013, 3-4), because 'listening to songs is as easy as driving a car' but '[u]nderstanding how they work is as hard as being a mechanic' (Moore 2012, 1), or because emotionality in music is difficult to analyse, for 'it's not clear what the emotions are about' (Ball 2010, 264). Often, when audience experiences have been theorised, they have not been empirically confirmed with the listeners, which has resulted in imagined dichotomies of listening: 'deep' versus 'superficial', 'conscious' versus 'background', 'everyday' versus 'special', 'motivated by aesthetic pleasure' versus 'motivated by goal achievement' (Zaborowski 2015, 100). In reality, everyday listening is rarely so strictly confined to modes and exclusive categories. Live audiences experience music mediated and filtered through a plethora of factors, personal stereo playlists can be both 'background' companions in daily routines and 'foreground' experiences of focus, and listening to supermarket muzak may be accidental, but need not be 'passive' (whatever the latter term should mean).

The richness of the study subject is, then, partly from where this special issue takes its name. Originally, the plural form of music was used to describe the richness and diversity of world music outside the "Western" paradigm (Manuel 1988, Coplan 1997), but nowadays the term 'musics' is the more relevant to emphasise the complexity of organised sound in everyday life. Just as the findings of audience research caused scholars to consider 'audiences' instead of 'audience' to underline the fact that audiences are fragmented and multiple (Livingstone 
1998), I propose that we now may need 'musics' to break off the unproductive dichotomies discussed above and see the listening experience as a spectrum of practices and interpretations. This, certainly, further widens the already complicated scope of enquiry and leads us to consider listening through a number of epistemological pathways.

Perhaps this is why, with an overall strong focus on music audiences, methodologically and conceptually this is a fantastically diverse issue, encompassing qualitative and quantitative methods (including questionnaires, diaries, focus group and in-depth interviews as well as observation) and interdisciplinary approaches (spanning from sociology, media and communication studies, cultural studies to music performance studies). The featured articles make important contributions to the area of music audience approach, discussing musics as social and cultural practices, but also as performances, texts, and cultural artefacts. In addition to four full-length, peer-reviewed articles, this special issue also includes an interview with the always inspiring Martin Barker and an insightful review of David Hesmondhalgh's monograph, Why Music Matters.

In our first article, Lucy Dearn and Sarah Price begin where many studies of music audiences start: with listening experiences of concert-goers. However, where much of such scholarship focuses solely on aesthetics and personal uses, the authors of 'Sharing Music: Social and Communal Aspects of Concert-Going' go beyond that to emphasise that experiences of classical concert listeners are also strongly linked to the social contexts and to the nature of the community of attendees. While Dearn and Price distinguish between short-term and longterm communal aspects of concert audiencing, they use their unique empirical data to argue that regardless of the length of the engagement, the experience is always linked to the social sphere of interaction.

In 'Mobile Music Listening: The Users and their Art of Making Do', Lionel Detry engages with practices of mobile music listening through an ethnographic approach. Detry argues that to understand practices, we need to look at the situation with the listening environment as well as the technology. This conceptual frame is chosen because mobile listening is unstable, unpredictable, and is never 'just' listening, but links to the ideas of performance and production. Detry's findings thus problematize the concept of creativity, which is especially relevant for audience studies in the time of media convergence.

In the third article, Steffen Lepa and Markus Seifert take on a challenging task of relating the concepts of generations and gender with genre preferences, modality and music listening habits. In 'Embodied Listening Modes as Part of Habitual Music Media Orientations', the authors analyse the strategies and audio repertoires of their two cohorts, 'Digital Mobilists' and 'Versatile Audiophiles'. Lepa and Seifert argue that the everyday listening modes they identify are strongly linked to social practices not necessarily related directly to music, while accounts of young people's early experiences of sound may help us understand later musical habits of their adult lives.

In 'A Holistic Approach to the Mechanisms of Music Engagement', our fourth article, Anna Ibañez Cantí starts with the circuit of culture model, Bourdieu's habitus and the relation between production and consumption as constant feedback of meaning. Through questionnaires and in-depth interviews with listeners, Ibañez Cantí revisits the concept of taste and inquires about how genre preferences map onto meanings derived from/through music, which include emotional regulation, spiritual experiences, companionship and intellectual satisfaction. 
Following the articles is my interview with Martin Barker on the potential of sound and music studies for media and audience research. Conducted in January 2015 during the annual MeCCSA conference in Newcastle, the conversation starts with a discussion of Barker's studies of audience experiences with organised sound, but the talk soon moves onto wider implications of researching the audible. Taking the reading on a tour across a range of interdisciplinary academic works, Barker hints that researching sound is key to understanding elusive aspects of media and audience research, but he also remains wary of methodological and conceptual challenges along the way.

Closing the issue is Li Zhongwei with his book review of Why Music Matters by David Hesmondhalgh. Li carefully analyses Hesmondhalgh's 'critical defense of music' in neoliberalism and sees the value of the monograph in its impressive scope and interdisciplinarity, and, more specifically, in complicating the concepts of the private and the public as not dichotomies, but rather areas on a spectrum, revealed to us precisely through music.

As this brief summary suggests, the special issue is rich in its diversity and valuable for (among other things) mapping some of the conceptual and methodological challenges of this nuanced field. The sheer empirical material critically discussed and related to a spectrum of disciplines and fields presents a strong case for why music listening research is relevant and needed. To the reader, this issue makes clear, I hope, that we do require new approaches to listening and to music - but also that this is a challenge for long years ahead.

\section{Acknowledgements}

I would like to thank all the authors for their hard work, inspiring ideas and lots of patience. A huge thank you is due to the peer-reviewers for their careful reading of the articles and always constructive comments - all delivered very swiftly. This issue wouldn't be possible without the Networking Knowledge editors: Sam Ward, who accepted my proposal for this issue, and Simon Dawes, who aided me throughout the process from the call for papers to publication.

\section{References}

Ball, P. (2010) The Music Instinct, New York: Oxford University Press.

Bull, M. (2000) Sounding out the City: Personal Stereos and the Management of Everyday Life, Oxford: Berg.

Coplan, D. (1997) 'Musics', International Social Science Journal, 49(154), 585-596.

DeNora, T. (2000) Music in Everyday Life, Cambridge, UK: Cambridge University Press. 
Lacey, K. (2013) Listening Publics: The Politics and Experience of Listening in the Media Age, Cambridge, UK: Polity Press.

Livingstone, S. (2003) 'The Changing Nature of Audiences: From the Mass Audience to the Interactive Media User', in A. Valdivia (ed.) Companion to Media Studies. Blackwell Companions in Cultural Studies, Oxford, UK: Blackwell Publishing, pp. 337-359.

Manuel, P. (1988) Popular Musics of the Non-Western World: An Introductory Survey, Oxford: Oxford University Press.

Moores, S. (2012) Media, Place and Mobility, London and New York: Palgrave Macmillan.

Zaborowski, R. (2015) 'Audible Audiences: Engaging with Music in Japan', PhD thesis, The London School of Economics and Political Science (LSE). http://etheses.Ise.ac.uk/id/eprint/3219.

Rafal Zaborowski is an LSE Fellow in the Department of Media and Communications at the London School of Economics and Political Science, where he teaches on media audiences, qualitative methodology and media development. Rafal is interested in music reception and social practices of listening, the co-evolution of media audiences and media institutions as well as in critical, qualitative methods of academic inquiry. Rafal holds a $\mathrm{PhD}$ in Media and Communications from the London School of Economics and Political Science, an MA in International Cultural Studies from Tohoku University, Japan, and a BA in Sociology from Ritsumeikan Asia Pacific University, Japan.

Email: r.zaborowski@1se.ac.uk 